\title{
Left atrial volume as an independent predictor of exercise capacity in patients with isolated diastolic dysfunction presented with exertional dyspnea
}

\author{
Nithima Ratanasit ${ }^{*}$, Khemajira Karaketklang $^{2}$, Srisakul Chirakarnjanakorn', Rungroj Krittayaphong ${ }^{1}$ \\ and Decho Jakrapanichakul ${ }^{1}$
}

\begin{abstract}
Background: Left atrial volume (LAV) and exercise capacity are important prognostic determinants of cardiovascular risk. Exercise intolerance and increased LAV are expected in patients with diastolic dysfunction. While dyspnea is the symptom reported by the patient and considered subjective, exercise capacity obtained by exercise testing provides an objective measure of cardiovascular fitness. The objective of this study is to determine the relationship between LAV index and exercise capacity in patients with isolated diastolic dysfunction who presented with exertional dyspnea.
\end{abstract}

Methods: We studied consecutive patients with dyspnea who underwent treadmill exercise testing and transthoracic echocardiography on the same day. LAV was assessed using the biplane area-length method. Symptom-limited exercise testing was performed immediately after echocardiography. Patients with coronary artery disease, valvular or congenital heart disease, left ventricular systolic dysfunction, pulmonary hypertension or positive exercise test were excluded.

Results: The study consisted of 111 patients ( $58.1 \pm 9.2$ years of age, $54.1 \%$ male, $64 \%$ hypertension, $57.7 \%$ dyslipidemia and $20.7 \%$ diabetes). The exercise duration and capacity were $6.8 \pm 2.1$ minutes and $7.7 \pm 1.9$ METs, respectively. Left ventricular ejection fraction and LAV index was $71.0 \pm 5.8 \%$ and $31.4 \pm 10.5 \mathrm{ml} / \mathrm{m}^{2}$, respectively. In multivariate analysis, age [odds ratios (OR) 0.94; 95\% confidence interval (Cl) 0.89-0.99], body mass index (OR 0.82, 95\% Cl 0.72-0.93), and LAV index (OR 0.92, 95\% Cl 0.87-0.97) were associated with good exercise capacity.

Conclusion: In patients with isolated diastolic dysfunction and exertional dyspnea, an increased LAV index, a marker of chronic diastolic dysfunction, is associated with poor exercise capacity.

Keywords: Left atrial volume, Exercise capacity, Diastolic dysfunction, Dyspnea

\section{Background}

Exercise capacity has been known to be an important prognostic determinant of cardiovascular and overall mortality $[1,2]$. The peak exercise capacity achieved during exercise testing is even more powerful than other established risk factors for cardiovascular disease such as hypertension, smoking, and diabetes mellitus [1]. Dyspnea is a classic symptom of heart failure. However, it is a subjective symptom with multiple potential etiologies,

\footnotetext{
* Correspondence: nithima.cha@mahidol.ac.th

'Division of Cardiology, Department of Medicine, Siriraj Hospital, Mahidol University, Bangkok 10700, Thailand

Full list of author information is available at the end of the article
}

not solely due to increased filling pressure. It may be a manifestation of diastolic dysfunction or other noncardiac conditions, such as pulmonary disease, obesity, anemia, endocrine disorders, physical deconditioning, or psychological disorder, and may as well limit exercise tolerance. Several studies have provided data on the significance of left ventricular (LV) diastolic dysfunction. The number of patients with heart failure in the presence of preserved systolic function was reported in $30-40 \%$ and LV diastolic dysfunction may be the underlying cause of symptoms in such patients [3]. While dyspnea is the subjective symptom reported by the patient, exercise capacity obtained by exercise testing provides an objective measure 
of quality of life, physical-activity status and cardiovascular fitness. Poor physical fitness is a modifiable risk factor, and the improvement in cardiovascular fitness has been demonstrated to improve prognosis [4].

Previous studies have shown that LV diastolic function is an important determinant of exercise capacity in normal individuals and patients with various heart diseases [5-10]. The assessment of LV diastolic function can be performed noninvasively by the conventional echocardiography and tissue Doppler imaging (TDI). Left atrial volume (LAV) has been recognized as an indicator of chronic diastolic dysfunction $[11,12]$. Increased LAV has been shown to be associated with cardiovascular risk burden and an increased risk of atrial fibrillation, stroke, heart failure and death [11-14]. Therefore, we hypothesized that an increased LAV and some echocardiographic indices of LV diastolic dysfunction would correlate with poor exercise capacity in patients with dyspnea of unknown origin.

\section{Methods \\ Study population}

Patients with the complaint of shortness of breath who were referred for treadmill exercise testing and transthoracic echocardiography at Siriraj Hospital were prospectively enrolled in the study. The exercise testing was performed immediately after the echocardiographic examination. Eligible patients were adults patients, in sinus rhythm, and able to exercise on the treadmill. The patients with known coronary artery disease, history of clinical heart failure, moderate or severe valvular heart disease, congenital heart disease, history of coronary revascularization or any prior cardiac surgery, LV systolic dysfunction (ejection fraction $<50 \%$ ), significant pulmonary hypertension (right ventricular systolic pressure > $50 \mathrm{mmHg}$ ), end-stage renal disease waiting for renal transplantation, pulmonary, hepatic or hematologic diseases were excluded from the study. The positive result of treadmill exercise testing and the echocardiographic detection of regional wall motion abnormality were also the exclusion criteria. The institutional review board of Siriraj Hospital approved the study protocol. Informed consent was obtained from all patients.

\section{Echocardiography}

Each participant underwent a comprehensive transthoracic echocardiographic examination with two-dimensional, M-mode, Doppler echocardiography and TDI. The measurement of echocardiographic parameters was performed on 3-5 consecutive cardiac cycles and the average was used for the analysis. The LV end-systolic and enddiastolic dimensions and wall thickness were measured using M-mode tracing. The LV end-systolic and enddiastolic volume and LV ejection fraction were determined using the Modified Simpson's rule (biplane) [15]. The LV diastolic function was assessed by Doppler echocardiography of transmitral flow velocities and TDI of the mitral annulus. Peak early (E) and late (A) diastolic velocities of mitral inflow and deceleration time of $\mathrm{E}$ were measured using pulsed-wave Doppler with the sample volume at the tip of mitral valve. The TDI determination of diastolic function was performed in apical 4-chamber view with the sample volume at the septal aspect of mitral annulus. Longitudinal early (E') and late (A') diastolic myocardial velocities were measured. The $\mathrm{E} / \mathrm{A}$ and $\mathrm{E} / \mathrm{E}$ ' ratio were calculated. Left atrial (LA) dimension was measured by M-mode echocardiography from the parasternal shortaxis view at end-systole. LAV was determined using the biplane area-length method and LV mass was calculated as recommended by the American Society of Echocardiography [15]. LAV and LV mass were indexed for body surface area. LA enlargement was defined as LAV index $\geq$ $29 \mathrm{ml} / \mathrm{m}^{2}$ as recommended by the American Society of Echocardiography [15]. Similarly, in the present study, the best cutoff value of LAV index for predicting good exercise capacity from the receiver operating characteristic curve (ROC) analysis was $29 \mathrm{ml} / \mathrm{m}^{2}$.

\section{Treadmill exercise testing}

Symptom-limited treadmill exercise testing with the Bruce protocol was performed to assess the patients' maximal exercise capacity. All patients were encouraged to exercise to maximal effort. The physician who was unaware of the echocardiographic results was present during exercise testing. Patients were instructed to continue their current medications on the day of testing. The predetermined end points of exercise testing were a positive test or maximal exercise capacity. Heart rate was recorded from a continuous 12-lead ECG monitoring. The age-predicted maximal heart rate was calculated as 220-age. Target heart rate was defined as $85 \%$ of the age-predicted maximal heart rate. The exercise time was recorded. Maximal exercise capacity was defined by the achieved metabolic equivalents (METs), which equal $3.5 \mathrm{~mL}$ of oxygen uptake per kilogram of body weight per minute and was estimated from exercise time as METs $=1.1+(0.016 \times$ exercise time in seconds) [16]. Patients with good exercise capacity were defined as those achieved $\geq 7$ METs [16]. Rate pressure product was calculated as the product of heart rate and systolic blood pressure at peak exercise.

\section{Statistical analysis}

Clinical, exercise and echocardiographic data were described using descriptive statistics, including means, standard deviation, number and percentage. The Student's ttest was used to compare continuous variables between 2 groups of patients. Comparison of categorical variables was performed using the Chi-square test. The ROC 
analysis was performed to determine the cutoff values of LAV index for predicting good exercise capacity. Univariate binary logistic regression analysis was used to assess the relationship between good exercise capacity and other variables. Multiple binary logistic regression analysis was performed using metabolic equivalent (good exercise capacity) as the dependent variable. Risk factors or independent variables (age in years, body mass index, peak heart rate, LA diameter, LAV index, A, E', E/E', LV mass index) were selected on the basis of clinical and statistical significances. The model was fitted by backward stepwise method for variable selection in and out of the model. All p-values are reported as 2-tailed, except where otherwise indicated. A p-value of $\leq 0.05$ was considered statistically significant. Statistical analyses were performed using SPSS statistical package version 18.0.

\section{Results}

The study consisted of 111 patients $(58.1 \pm 9.2$ years of age, $54.1 \%$ male). LA enlargement was observed in 59 (53.2\%) patients. The patients were classified into 2 groups according to the presence of LA enlargement. Clinical characteristics in all patients and patients grouped according to the presence of LA enlargement are shown in Table 1. Patients with LA enlargement were significantly older. However, gender, body mass index, coronary risk factors and current medications were not significantly different between the 2 groups.

\section{Echocardiographic data}

All patients had good LV systolic function with LV ejection fraction of $71.0 \pm 5.8 \%$. The right ventricular systolic

\section{Table 1 Clinical characteristics of all patients and the comparisons between patients with and without left atrial enlargement}

\begin{tabular}{ccccc}
\hline Variables & $\begin{array}{c}\text { Total } \\
(\mathbf{N}=\mathbf{1 1 1})\end{array}$ & $\begin{array}{c}\mathbf{L A V I}<\mathbf{2 9} \mathbf{~ \mathbf { l }} / \mathbf{m}^{\mathbf{2}} \\
(\mathbf{N}=\mathbf{5 2})\end{array}$ & $\begin{array}{c}\mathbf{L A V I} \geq \mathbf{2 9} \mathbf{~ \mathbf { l }} / \mathbf{m}^{\mathbf{2}} \\
(\mathbf{N}=\mathbf{5 9})\end{array}$ & P-value \\
\hline Age (years) & $58.1 \pm 9.2$ & $55.9 \pm 8.8$ & $60.1 \pm 9.2$ & 0.018 \\
Male gender & $60(54.1)$ & $30(57.7)$ & $30(50.8)$ & 0.470 \\
BMI (kg/m $\left.{ }^{2}\right)$ & $25.7 \pm 3.8$ & $25.6 \pm 3.3$ & $25.7 \pm 4.1$ & 0.960 \\
Hypertension & $71(64.0)$ & $31(59.6)$ & $40(67.8)$ & 0.370 \\
Diabetes & $23(20.7)$ & $9(17.3)$ & $14(23.7)$ & 0.405 \\
mellitus & & & & \\
Smoking & $9(8.1)$ & $5(9.6)$ & $4(6.8)$ & 0.732 \\
Dyslipidemia & $64(57.7)$ & $33(63.5)$ & $31(52.5)$ & 0.245 \\
Betablocker & $50(45.0)$ & $22(42.3)$ & $28(47.5)$ & 0.586 \\
ACEl/ARB & $40(36.0)$ & $19(37.3)$ & $21(35.6)$ & 0.857 \\
Diuretics & $9(8.1)$ & $3(5.7)$ & $6(10.2)$ & 0.503 \\
\hline
\end{tabular}

Data are expressed as mean \pm standard deviation and number (percentage). $P$ values are for comparisons between 2 groups.

$\mathrm{ACEI} / \mathrm{ARB}=$ Angiotensin converting enzyme inhibitor/angiotensin receptor blocker; $\mathrm{BMI}=$ Body mass index; $\mathrm{LAVI}=$ Left atrial volume index. pressure was $31.7 \pm 6.5 \mathrm{mmHg}$. All patients had diastolic dysfunction; abnormal relaxation and pseudonormalization pattern in $64.9 \%$ and $35.1 \%$, respectively. No patient had an advanced stage of diastolic dysfunction (restrictive filling pattern). LAV index and LV mass index were $31.4 \pm 10.5 \mathrm{ml} / \mathrm{m}^{2}$ and $110.2 \pm 40.1 \mathrm{gm} / \mathrm{m}^{2}$, respectively. The echocardiographic data are present in Table 2. Patients with LA enlargement significantly presented with more LV hypertrophy, larger LV end-diastolic dimension and volume, and more severe diastolic dysfunction (lower E' and higher E/E') than those without.

\section{Exercise hemodynamics}

The results of exercise testing are presented in Table 3. Achieving target heart rate was reported in $57.7 \%$ of patients. More patients without LA enlargement achieved target heart rate than those with LA enlargement $(69.2 \%$ vs. $47.5 \%, \mathrm{p}=0.021$ ). Regarding exercise capacity, the number of patients who achieved target heart rate was similar between those with and without good exercise capacity $(60.3 \%$ vs. $52.6 \%, \mathrm{p}=0.439)$. Good exercise capacity was reported in $65.8 \%$ of patients. More patients without LA enlargement had good exercise capacity than those with LA enlargement $(82.7 \%$ vs. $50.8 \%, \mathrm{p}<0.001)$. The absolute exercise capacity was significantly better in patients without LA enlargement $(8.3 \pm 1.7$ vs. $7.3 \pm 2.0$, $\mathrm{p}=0.005)$. No serious complication occurred during treadmill exercise testing.

\section{Determinants of exercise capacity}

Regarding exercise capacity, the patients were further categorized as those with and without good exercise capacity. Table 4 shows the clinical, exercise and echocardiographic parameters of all patients and the comparisons between patients with and without good exercise capacity. There were no statistically significant differences between patients with and without good exercise capacity in term of the number of male gender, hypertension, diabetes mellitus, dyslipidemia, smoking, rest and peak systolic and diastolic blood pressure, and grade of diastolic dysfunction. The results of univariate and multivariate binary logistic regression analysis are shown in Table 5. LAV index remained an independent predictor of good exercise capacity. In univariate analysis, age, body mass index, peak heart rate, $\mathrm{A}, \mathrm{E}, \mathrm{E} / \mathrm{E}$ ' ratio, LA dimension, $\mathrm{LV}$ mass index and LAV index showed a significant association with good exercise capacity. By multiple logistic regression analysis, age [odds ratios (OR) 0.94; 95\% confidence interval (CI) 0.89-0.99], body mass index (OR 0.82, 95\% CI 0.72-0.93), and LAV index (OR 0.92, 95\% CI 0.87-0.97) were associated with good exercise capacity (Table 5). In the present study, the cutoff value of LAV index of $29 \mathrm{ml} / \mathrm{m}^{2}$ predicted good exercise capacity with the sensitivity, specificity, predictive accuracy of positive and negative results of 
Table 2 Echocardiographic parameters of all patients and the comparisons between patients with and without left atrial enlargement

\begin{tabular}{|c|c|c|c|c|}
\hline Variables & Total $(n=111)$ & $\mathrm{LAVI}<29 \mathrm{ml} / \mathrm{m}^{2}(\mathrm{n}=52)$ & $\mathrm{LAVI} \geq 29 \mathrm{ml} / \mathrm{m}^{2}(\mathrm{n}=59)$ & P-value \\
\hline LVDD (mm) & $48.2 \pm 4.8$ & $47.1 \pm 3.7$ & $49.1 \pm 5.4$ & 0.026 \\
\hline LVSD (mm) & $27.9 \pm 5.3$ & $27.7 \pm 4.3$ & $28.0 \pm 6.0$ & 0.814 \\
\hline IVSd (mm) & $10.9 \pm 2.6$ & $10.3 \pm 2.4$ & $11.4 \pm 2.7$ & 0.025 \\
\hline LVEDV (ml) & $68.8 \pm 16.6$ & $65.0 \pm 13.9$ & $72.1 \pm 18.1$ & 0.023 \\
\hline LVESV (ml) & $20.2 \pm 8.0$ & $19.4 \pm 7.5$ & $20.8 \pm 8.4$ & 0.380 \\
\hline LV ejection fraction (\%) & $71.1 \pm 5.8$ & $70.7 \pm 5.1$ & $71.5 \pm 6.4$ & 0.450 \\
\hline LV mass index $\left(\mathrm{g} / \mathrm{m}^{2}\right)$ & $110.2 \pm 40.1$ & $96.0 \pm 22.1$ & $123.0 \pm 47.8$ & $<0.001$ \\
\hline LA diameter (mm) & $43.0 \pm 6.1$ & $39.6 \pm 5.0$ & $46.1 \pm 5.3$ & $<0.001$ \\
\hline $\mathrm{E}(\mathrm{cm} / \mathrm{sec})$ & $79.4 \pm 23.7$ & $76.1 \pm 21.0$ & $82.3 \pm 25.8$ & 0.168 \\
\hline $\mathrm{A}(\mathrm{cm} / \mathrm{sec})$ & $84.8 \pm 23.5$ & $80.5 \pm 21.8$ & $88.6 \pm 24.4$ & 0.068 \\
\hline E/A ratio & $1.0 \pm 0.4$ & $1.0 \pm 0.4$ & $0.9 \pm 0.3$ & 0.549 \\
\hline DT (ms) & $201.3 \pm 40.7$ & $197.7 \pm 29.6$ & $204.6 \pm 48.6$ & 0.364 \\
\hline $\mathrm{S}^{\prime}(\mathrm{cm} / \mathrm{sec})$ & $7.0 \pm 1.3$ & $7.2 \pm 1.4$ & $6.9 \pm 1.3$ & 0.136 \\
\hline $\mathrm{E}^{\prime}(\mathrm{cm} / \mathrm{sec})$ & $6.1 \pm 1.6$ & $6.4 \pm 1.7$ & $5.8 \pm 1.3$ & 0.033 \\
\hline E/E'ratio & $13.6 \pm 4.6$ & $12.1 \pm 3.0$ & $14.9 \pm 5.4$ & 0.001 \\
\hline \multicolumn{5}{|l|}{ Diastolic dysfunction } \\
\hline - Abnormal relaxation & $72(64.9)$ & $32(61.5)$ & $40(67.8)$ & 0.491 \\
\hline - Pseudonormalization & $39(35.1)$ & $20(38.5)$ & $19(32.2)$ & \\
\hline
\end{tabular}

Data are expressed as number (percentage) or mean \pm standard deviation.

$P$ values are for comparisons between 2 groups.

$A$ = peak late diastolic velocity of mitral inflow; $D T=$ deceleration time; $E$ = peak early diastolic velocity of mitral inflow; $E^{\prime}=$ tissue Doppler peak early diastolic velocity of medial mitral annulus; IVSd = interventricular septum wall thickness during diastole; $L A=$ left atrium; $L A V I=$ left atrial volume index; $L V=$ left ventricle; LVDD = left ventricular end-diastolic diameter; LVSD = left ventricular end-systolic diameter; LVEDV = left ventricular end-diastolic volume; LVESV = left ventricular end-systolic volume; $\mathrm{S}^{\prime}=$ tissue Doppler peak systolic velocity of medial mitral annulus.

76.3\%, 58.9\%, 49.2\% and $82.7 \%$, respectively, according to ROC analysis (AUC $=0.69$ (95\% CI: 0.59 to 0.80$)$ ). Furthermore, the patients were classified as either having or not having LA enlargement and categorized into 2 groups according to the cutoff value of LAV index of $29 \mathrm{ml} / \mathrm{m}^{2}$.
Clinical characteristics, echocardiographic and exercise parameters in patients with and without LA enlargement are shown in Tables 1, 2 and 3, respectively. LAV index correlated with exercise capacity $(\mathrm{r}=-0.33, \mathrm{p}<0.001)$ (Figure 1).

Table 3 Exercise parameters of all patients and the comparisons between patients with and without left atrial enlargement

\begin{tabular}{|c|c|c|c|c|}
\hline Variables & Total $(n=111)$ & $\mathrm{LAVI}<29 \mathrm{ml} / \mathrm{m}^{2}(\mathrm{n}=52)$ & $\mathrm{LAVI} \geq 29 \mathrm{ml} / \mathrm{m}^{2}(\mathrm{n}=59)$ & P-value \\
\hline Rest HR (beats/min) & $70.7 \pm 14.4$ & $74.4 \pm 15.7$ & $67.5 \pm 12.5$ & 0.012 \\
\hline Peak HR (beats/min) & $137.2 \pm 24.5$ & $145.1 \pm 22.0$ & $130.1 \pm 24.5$ & 0.001 \\
\hline Rest SBP (mmHg) & $145.6 \pm 19.3$ & $139.9 \pm 17.9$ & $150.5 \pm 19.4$ & 0.003 \\
\hline Peak SBP (mmHg) & $209.4 \pm 40.9$ & $204.7 \pm 38.8$ & $213.5 \pm 42.6$ & 0.258 \\
\hline Rest DBP (mmHg) & $79.7 \pm 12.8$ & $78.1 \pm 13.4$ & $81.0 \pm 12.3$ & 0.236 \\
\hline Peak DBP (mmHg) & $87.9 \pm 18.7$ & $86.8 \pm 17.2$ & $88.8 \pm 20.1$ & 0.583 \\
\hline Rate-pressure products & $28566.9 \pm 8300.4$ & $29515.1 \pm 7832.7$ & $27731.2 \pm 8671.9$ & 0.282 \\
\hline Exercise duration (minutes) & $6.8 \pm 2.1$ & $7.4 \pm 1.8$ & $6.3 \pm 2.1$ & 0.005 \\
\hline Exercise capacity (METs) & $7.7 \pm 1.9$ & $8.3 \pm 1.7$ & $7.3 \pm 2.0$ & 0.005 \\
\hline Exercise capacity $>7$ METs & $73(65.8)$ & $43(82.7)$ & $30(50.8)$ & $<0.001$ \\
\hline
\end{tabular}

Data are expressed as mean \pm standard deviation and number (percentage).

$P$ values are for comparisons between the 2 groups.

$\mathrm{DBP}=$ diastolic blood pressure; $\mathrm{HR}=$ heart rate; $\mathrm{LAVI}=$ left atrial volume index; $\mathrm{METs}=$ metabolic equivalents; $\mathrm{SBP}=$ systolic blood pressure. 
Table 4 Clinical, exercise and echocardiographic parameters of all patients and the comparisons between patients with and without good exercise capacity

\begin{tabular}{|c|c|c|c|c|}
\hline Variables & Total $(n=111)$ & Exercise capacity $<7$ METs $(n=38)$ & Exercise capacity $\geq 7$ METs $(n=73)$ & P-value \\
\hline Age (years) & $58.1 \pm 9.2$ & $61.7 \pm 9.2$ & $56.3 \pm 8.7$ & 0.003 \\
\hline Male gender & $60(54.1)$ & $20(52.6)$ & $40(54.8)$ & 0.828 \\
\hline $\mathrm{BMI}\left(\mathrm{kg} / \mathrm{m}^{2}\right)$ & $25.7 \pm 3.8$ & $27.1 \pm 4.0$ & $24.9 \pm 3.4$ & 0.004 \\
\hline Rest HR (beats/min) & $70.7 \pm 14.4$ & $70.8 \pm 15.5$ & $70.7 \pm 14.0$ & 0.975 \\
\hline Peak HR (beats/min) & $137.2 \pm 24.5$ & $127.3 \pm 23.2$ & $142.3 \pm 23.7$ & 0.002 \\
\hline LVDD (mm) & $48.2 \pm 4.8$ & $49.0 \pm 5.5$ & $47.8 \pm 4.4$ & 0.238 \\
\hline $\operatorname{LVSD}(\mathrm{mm})$ & $27.9 \pm 5.3$ & $28.4 \pm 6.3$ & $27.6 \pm 4.6$ & 0.457 \\
\hline IVSd (mm) & $10.9 \pm 2.6$ & $11.6 \pm 3.1$ & $10.5 \pm 2.2$ & 0.053 \\
\hline LVEDV (ml) & $68.8 \pm 16.6$ & $71.7 \pm 19.9$ & $67.2 \pm 14.4$ & 0.175 \\
\hline LVESV (ml) & $20.2 \pm 8.0$ & $21.4 \pm 9.5$ & $19.5 \pm 7.0$ & 0.220 \\
\hline LV ejection fraction (\%) & $71.1 \pm 5.8$ & $70.8 \pm 6.4$ & $71.3 \pm 5.5$ & 0.644 \\
\hline LV mass index $\left(\mathrm{g} / \mathrm{m}^{2}\right)$ & $110.2 \pm 40.1$ & $124.4 \pm 55.4$ & $103.1 \pm 27.2$ & 0.032 \\
\hline LA diameter (mm) & $43.0 \pm 6.1$ & $45.8 \pm 5.2$ & $41.7 \pm 6.0$ & 0.001 \\
\hline $\mathrm{E}(\mathrm{cm} / \mathrm{sec})$ & $79.4 \pm 23.7$ & $82.9 \pm 24.1$ & $77.6 \pm 23.5$ & 0.261 \\
\hline $\mathrm{A}(\mathrm{cm} / \mathrm{sec})$ & $84.8 \pm 23.5$ & $93.1 \pm 24.7$ & $80.5 \pm 21.8$ & 0.006 \\
\hline E/A ratio & $1.0 \pm 0.4$ & $0.9 \pm 0.3$ & $1.0 \pm 0.4$ & 0.221 \\
\hline DT (ms) & $201.3 \pm 40.7$ & $205.5 \pm 48.8$ & $199.1 \pm 35.9$ & 0.438 \\
\hline $\mathrm{S}^{\prime}(\mathrm{cm} / \mathrm{sec})$ & $7.0 \pm 1.3$ & $6.8 \pm 1.3$ & $7.2 \pm 1.3$ & 0.101 \\
\hline $\mathrm{E}^{\prime}(\mathrm{cm} / \mathrm{sec})$ & $6.1 \pm 1.6$ & $5.6 \pm 1.2$ & $6.3 \pm 1.7$ & 0.007 \\
\hline E/E'ratio & $13.6 \pm 4.6$ & $15.2 \pm 5.5$ & $12.7 \pm 3.8$ & 0.006 \\
\hline LAVI $\left(\mathrm{ml} / \mathrm{m}^{2}\right)$ & $31.4 \pm 10.5$ & $36.3 \pm 12.8$ & $28.8 \pm 8.0$ & 0.002 \\
\hline
\end{tabular}

Data are expressed as number (percentage) or mean \pm standard deviation.

$P$ values are for comparisons between 2 groups.

$\mathrm{A}=$ peak late diastolic velocity of mitral inflow; $\mathrm{BMI}=$ body mass index; $\mathrm{DT}=$ deceleration time; $\mathrm{E}=$ peak early diastolic velocity of mitral inflow; $\mathrm{E}^{\prime}=$ tissue Doppler peak early diastolic velocity of medial mitral annulus; $H R=$ heart rate; IVSd = interventricular septum wall thickness during diastole; $L A=$ left atrium; LAVI = left atrial volume index; LV = left ventricle; LVDD = left ventricular end-diastolic diameter; LVSD = left ventricular end-systolic diameter; LVEDV = left ventricular enddiastolic volume; LVESV = left ventricular end-systolic volume; METs = metabolic equivalents ; $\mathrm{S}^{\prime}=$ tissue Doppler peak systolic velocity of medial mitral annulus.

Table 5 Univariate and multivariate logistic regression analysis of parameters that associate with good exercise capacity

\begin{tabular}{|c|c|c|c|c|}
\hline & $\begin{array}{c}\text { Univariate } \\
\text { OR }(95 \% \mathrm{Cl}) \\
\end{array}$ & P-value & $\begin{array}{l}\text { Multivariate } \\
\text { OR }(95 \% \mathrm{Cl}) \\
\end{array}$ & P-value \\
\hline Age & 0.93 (0.88 to 0.98 ) & 0.004 & 0.94 (0.89 to 0.99 ) & 0.018 \\
\hline $\begin{array}{l}\text { Body mass } \\
\text { index }\end{array}$ & 0.85 (0.76 to 0.95 ) & 0.005 & 0.82 (0.72 to 0.93 ) & 0.002 \\
\hline $\begin{array}{l}\text { Peak heart } \\
\text { rate }\end{array}$ & 1.03 (1.01 to 1.05$)$ & 0.003 & - & \\
\hline A & 0.98 (0.96 to 0.99 ) & 0.009 & - & \\
\hline$E^{\prime}$ & $1.42(1.06$ to 1.91$)$ & 0.018 & - & \\
\hline $\mathrm{E} / \mathrm{E}^{\prime}$ ratio & 0.89 (0.81 to 0.97 ) & 0.009 & - & \\
\hline LA dimension & 0.88 (0.81 to 0.95 ) & 0.001 & - & \\
\hline LV mass index & 0.99 (0.98 to 0.99 ) & 0.015 & - & \\
\hline LAVI & 0.93 (0.88 to 0.97 ) & 0.001 & 0.92 (0.87 to 0.97 ) & 0.003 \\
\hline
\end{tabular}

$\mathrm{A}=$ peak late diastolic velocity of mitral inflow; $\mathrm{Cl}=$ confidence interval; $\mathrm{E}=$ peak early diastolic velocity of mitral inflow; $\mathrm{E}^{\prime}=$ tissue Doppler peak early diastolic velocity of medial mitral annulus; $L A=$ left atrium; $L A V I=$ left atrial volume index; $\mathrm{LV}=$ left ventricle; $\mathrm{OR}=$ odd ratio.

\section{Discussion}

The present study emphasizes the importance of LAV index as an independent echocardiographic predictor of exercise capacity in patients with dyspnea of unknown origin. Among several echocardiographic variables of diastolic function, A, E, E/E' and LAV index correlated significantly with exercise capacity. Interestingly, LAV index was found to be the only echocardiographic measure of diastolic function that represents an independent predictor of exercise capacity in this population.

\section{Diastolic dysfunction and exercise capacity}

Dyspnea on exertion or reduced exercise capacity is a major clinical problem in patients with LV diastolic dysfunction, more pronounced in diastolic heart failure. It is well known that LV diastolic dysfunction is common in patients with LV systolic dysfunction and Doppler variables of LV diastolic filling are better than LV systolic indices in predicting exercise capacity in patients with systolic heart failure $[9,10]$. Similarly, the correlations between the echocardiographic parameters of 


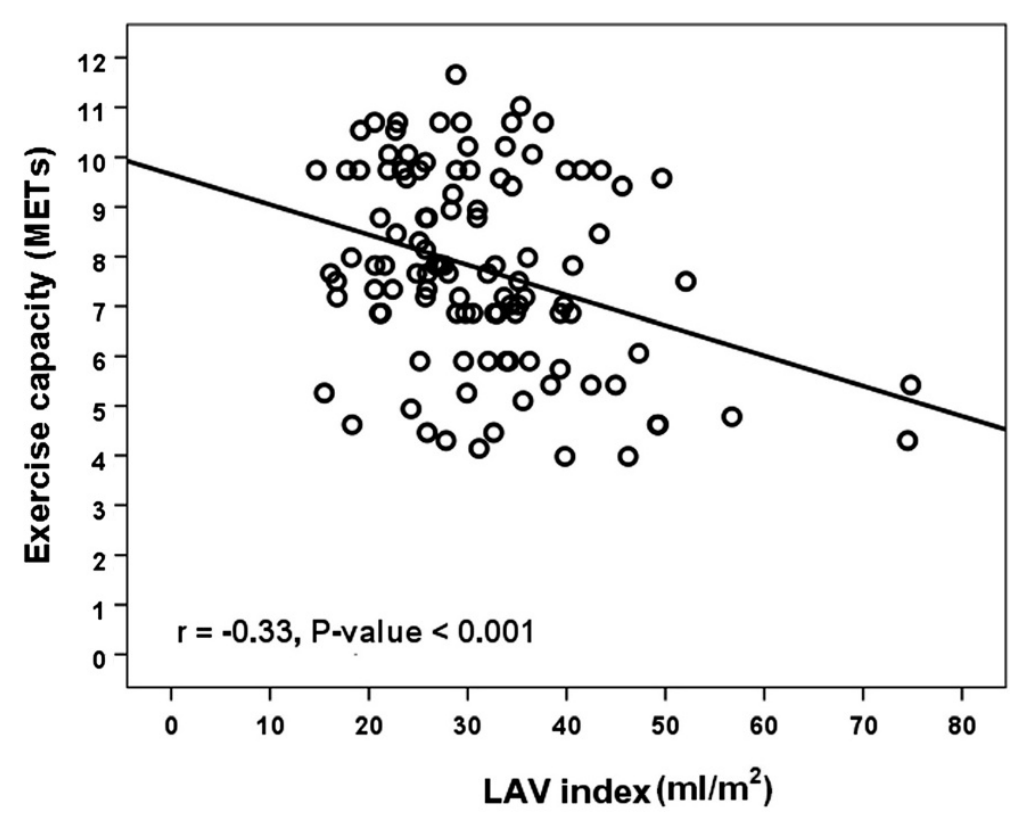

Figure 1 Correlation of left atrial volume (LAV) index with exercise capacity.

diastolic function and exercise capacity have been demonstrated in patients with isolated diastolic dysfunction $[6,7,11,17-20]$. Previous studies in patients with diabetes mellitus and hypertension showed that maximum exercise capacity was lower in those with diastolic dysfunction than in control subjects without diastolic dysfunction $[17,18]$. Several studies in patients with diastolic dysfunction, including the present study, demonstrated the strong and inverse association between exercise capacity/duration and some echocardiographic parameters of LV diastolic dysfunction, such as high E/E' or LA enlargement $[7,8,19,20]$. Among several measurable variables of diastolic dysfunction used to predict exercise capacity, LAV has been demonstrated as the most reliable and robust since its size correlates closely with an impaired LV filling and reflects the chronicity and severity to diastolic dysfunction [11]. Arruda AL et al. reported that LAV index negatively correlated with exercise capacity and the correlation was strongest in patients with isolated diastolic dysfunction as compared to those with systolic dysfunction or control subjects [19]. The findings of the present study were consistent with those of previous studies and demonstrated that the larger LAV index was independently associated with exercise intolerance.

\section{Left atrial enlargement as a biomarker of poor exercise capacity}

LA enlargement commonly occurs in the setting of LV diastolic dysfunction, is associated with the presence of cardiovascular disease and has been shown to be a poor prognostic indicator of adverse cardiovascular outcomes, such as atrial fibrillation, heart failure, stroke, and death
[11-14]. In the absence of LV systolic dysfunction, pulmonary hypertension, significant valvular disease or pericardial disease, patients with LV diastolic dysfunction commonly present with dyspnea on exertion or limited exercise capacity, presumably due to elevated pulmonary capillary pressure and LV filling pressure [21]. It is well known that correlations exist between exercise capacity and Doppler-derived indices of LV diastolic dysfunction, such as Doppler transmitral flow velocities and TDI of the mitral annulus $[5-8,18,19,21]$. However, data regarding LAV in predicting exercise capacity are more limited. The echocardiographic measurement of LAV is simple and may better reflect the severity and cumulative effect of LV filling pressure over longer time rather than Doppler-derived LV diastolic indices alone. Pritchett AM et al. reported in a study of the general population that LAV index was closely associated with the severity of diastolic dysfunction assessed by Doppler echocardiography [14]. The mechanism of LA enlargement in patients with isolated diastolic dysfunction is less convincing, but it has been hypothesized that diastolic dysfunction occurs as a consequence of cardiovascular diseases, such as LV hypertrophy from hypertension, and leads to chronic diastolic atrial pressure overload. Ultimately, LA enlargement and symptom of dyspnea are evident in patients with isolated diastolic dysfunction. Also, LA enlargement becomes a reliable indicator of advanced diastolic dysfunction, regardless of LV systolic function, underlying cardiovascular disease or LV hypertrophy [14]. Previous studies have emphasized the prognostic significance of LA enlargement in different populations [11,13]. Furthermore, Tsang TS et al. demonstrated that LAV index had a positive correlation 
with LV filling pressure as indicated by E/E' [11]. As exercise intolerance is a common clinical problem in patients with diastolic dysfunction, only few studies have demonstrated the association between LA enlargement and exercise capacity $[19,22,23]$. Previous study in patients with LV systolic dysfunction and heart failure showed that indexed LA diastolic and systolic size were independent predictors of exercise capacity and cardiovascular events (cardiac death or hospitalization for worsening heart failure), respectively [22]. However, the authors employed LA dimension, not LAV, in the study. LA remodeling is a continuous process as long as cardiovascular risk factors or diseases still persist in any individual. As chronic diastolic burden and LA remodeling continue over time, LA shape may become less spherical and LA volume may provide a more reliable and consistent representative of LA remodeling than LA dimension [12]. In a recent study by Vaturi $M$ et al., LA enlargement, defined as LAV index > $42 \mathrm{ml} / \mathrm{m}^{2}$, was associated with poor exercise capacity [23]. However, the study was conducted in asymptomatic patients with chronic volume overload of severe mitral regurgitation, whereas LA enlargement was expected. Another study in patients with isolated diastolic dysfunction showed that elevated LAV was predictive of exercise capacity and elevated ventilator responses, similar to Doppler indices of diastolic function [19]. The present study demonstrated the similar finding that LAV index significantly correlated with exercise capacity in patients with normal systolic function and dyspnea on exertion of unknown origin. However, there was no correlation among the subgroup of patients without LA enlargement. This finding emphasized the importance of LAV index in risk stratification for patients with dyspnea and diastolic dysfunction, especially those with chronic diastolic dysfunction as manifested by LA enlargement. Furthermore, recent studies have focused on the measurement of LA function using the speckle tracking method in patients with diastolic dysfunction $[24,25]$ and demonstrated that LA function was a significant correlate of exercise capacity, regardless of hemodynamic response to stress, in a large group of patients with preserved LV ejection fraction undergoing exercise echocardiography [25].

\section{Study limitations}

The present study has some limitations; including the relatively small sample size and the lack of complete cardiopulmonary exercise testing. Although the measurement of maximal oxygen consumption with direct gas exchange may be more accurate in the assessment of exercise capacity, the calculation of achieved METs is widely accepted for determining function capacity in routine clinical practice and has been shown to predict long term mortality in a large group of patients [1]. There is the potential for a referral bias that the study population may be those who seek medical attention and have more comorbidities than general population. The present study was not conducted in patients undergoing exercise stress echocardiography, but instead compared rest echocardiographic parameters with exercise capacity in patients undergoing echocardiography and treadmill exercise test. The immediate post-exercise echocardiographic variables may be a better predictor of exercise capacity, but were not available in the present study. The study employed the positive result of treadmill exercise testing and the echocardiographic detection of regional wall motion abnormality, not the coronary angiogram as a gold standard, to exclude coronary artery disease. Finally, more recent data on LA function using speckle tracking have been published and revealed promising results $[24,25]$. The technique has not yet been introduced to day-to-day practice in the echocardiographic laboratory and the measurement of LA function was not performed in the present study. However, the role of LA function, in addition or combination with LAV, in predicting exercise capacity or clinical outcomes warrants further study.

\section{Conclusions}

In patients with isolated diastolic dysfunction and exertional dyspnea, increased LAV index, a marker of chronic diastolic dysfunction, is associated with poor exercise capacity. Therefore, LAV index should be assessed as a part of routine echocardiographic examination and LA enlargement may become a part of clinical risk stratification in patients presented with exertional dyspnea.

\section{Abbreviations}

Cl: Confidence interval; LA: Left atrial; LAV: Left atrial volume; LV: Left ventricle; METs: Metabolic equivalents; OR: Odds ratios; ROC: Receiver operating characteristic; TDI: Tissue doppler imaging.

\section{Competing interests}

The authors declare that they have no competing interests.

\section{Authors' contributions}

NR, conceived the study, participated in study design, analyzed data, interpreted exercise and echocardiographic data, drafted and revised the manuscript; KK, performed statistical analysis; SC, performed exercise testing and collected data; RK analyzed data, drafted and revised the manuscript; DJ, interpreted echocardiographic data. All authors read and approved the final manuscript.

\section{Acknowledgements}

The authors are indebted to the study sonographers, Kesaree Punlee and Wandee Rochanasiri for their technical expertise, and Herbert M. Swick, M.D. for the manuscript preparation and grammatical editing.

\section{Author details}

'Division of Cardiology, Department of Medicine, Siriraj Hospital, Mahidol University, Bangkok 10700, Thailand. ²Department of Medicine, Siriraj Hospital, Mahidol University, Bangkok 10700, Thailand.

Received: 2 April 2014 Accepted: 5 June 2014

Published: 14 June 2014 


\section{References}

1. Myers J, Prakash M, Froelicher V, Do D, Partington S, Atwood JE: Exercise capacity and mortality among men referred for exercise testing. $N$ Engl J Med 2002, 346:793-801.

2. Roger VL, Jacobsen SJ, Pellikka PA, Miller TD, Bailey KR, Gersh BJ: Prognostic value of treadmill exercise testing: a population-based study in Olmsted County, Minnesota. Circulation 1998, 98:2836-2841.

3. Vasan RS, Benjamin EJ, Levy D: Prevalence, clinical features and prognosis of diastolic heart failure: an epidemiologic perspective. J Am Coll Cardiol 1995, 26:1565-1574.

4. Blair SN, Kohl HW 3rd, Barlow CE, Paffenbarger RS Jr, Gibbons LW, Macera CA: Changes in physical fitness and all-cause mortality. A prospective study of healthy and unhealthy men. JAMA 1995, 273:1093-1098.

5. Okura H, Inoue H, Tomon M, Nishiyama S, Yoshikawa T, Yoshida K, Yoshikawa J: Impact of Doppler-derived left ventricular diastolic performance on exercise capacity in normal individuals. Am Heart J 2000, 139:716-722.

6. Gharavi AG, Diamond JA, Goldman AY, Coplan NL, Jhang JS, Steinmetz M, Goldsmith R, Phillips RA: Resting diastolic function and left ventricular mass are related to exercise capacity in hypertensive men but not in women. Am J Hypertens 1998, 11:1252-1257.

7. Grewal J, McCully RB, Kane GC, Lam C, Pellikka PA: Left ventricular function and exercise capacity. JAMA 2009, 301:286-294.

8. Skaluba SJ, Litwin SE: Mechanisms of exercise intolerance: insights from tissue Doppler imaging. Circulation 2004, 109:972-977.

9. Terzi S, Sayar N, Bilsel T, Enc Y, Yildirim A, Ciloğlu F, Yesilcimen K: Tissue Doppler imaging adds incremental value in predicting exercise capacity in patients with congestive heart failure. Heart Vessels 2007, 22:237-244.

10. Gardin JM, Leifer ES, Fleg JL, Whellan D, Kokkinos P, Leblanc MH, Wolfel E, Kitzman DW, HF-ACTION Investigators: Relationship of DopplerEchocardiographic left ventricular diastolic function to exercise performance in systolic heart failure: the HF-ACTION study. Am Heart $J$ 2009, 158:S45-S52.

11. Tsang TS, Barnes ME, Gersh BJ, Bailey KR, Seward JB: Left atrial volume as a morphophysiologic expression of left ventricular diastolic dysfunction and relation to cardiovascular risk burden. Am J Cardiol 2002, 90:1284-1289.

12. Pritchett AM, Jacobsen SJ, Mahoney DW, Rodeheffer RJ, Bailey KR, Redfield MM: Left atrial volume as an index of left atrial size: a population-based study. J Am Coll Cardiol 2003, 41:1036-1043.

13. Benjamin EJ, D'Agostino RB, Belanger AJ, Wolf PA, Levy D: Left atrial size and the risk of stroke and death. The framingham heart study. Circulation 1995, 92:835-841.

14. Pritchett AM, Mahoney DW, Jacobsen SJ, Rodeheffer RJ, Karon BL, Redfield MM: Diastolic dysfunction and left atrial volume: a population-based study. J Am Coll Cardiol 2005, 45:87-92.

15. Lang RM, Bierig M, Devereux RB, Flachskampf FA, Foster E, Pellikka PA, Picard MH, Roman MJ, Seward J, Shanewise JS, Solomon SD, Spencer KT, Sutton MS, Stewart WJ: Recommendations for chamber quantification: a report from the American Society of Echocardiography's Guidelines and Standards Committee and the Chamber Quantification Writing Group, developed in conjunction with the European Association of Echocardiography, a branch of the European Society of Cardiology. J Am Soc Echocardiogr 2005, 18:1440-1463.

16. Fletcher GF, Balady GJ, Amsterdam EA, Chaitman B, Eckel R, Fleg J, Froelicher VF, Leon AS, Piña IL, Rodney R, Simons-Morton DA, Williams MA, Bazzarre T: Exercise standards for testing and training: a statement for healthcare professionals from the American Heart Association. Circulation 2001, 104:1694-1740.

17. Poirier P, Garneau C, Bogaty P, Nadeau A, Marois L, Brochu C, Gingras C, Fortin C, Jobin J, Dumesnil JG: Impact of left ventricular diastolic dysfunction on maximal treadmill performance in normotensive subjects with well-controlled type 2 diabetes mellitus. Am J Cardiol 2000, 85:473-477.

18. Dekleva M, Celic V, Kostic N, Pencic B, Ivanovic AM, Caparevic Z: Left ventricular diastolic dysfunction is related to oxidative stress and exercise capacity in hypertensive patients with preserved systolic function. Cardiology 2007, 108:62-70.

19. Arruda AL, Pellikka PA, Olson TP, Johnson BD: Exercise capacity, breathing pattern, and gas exchange during exercise for patients with isolated diastolic dysfunction. J Am Soc Echocardiogr 2007, 20:838-846.
20. Ha JW, Oh JK, Pellikka PA, Ommen SR, Stussy VL, Bailey KR, Seward JB, Tajik AJ: Diastolic stress echocardiography: a novel noninvasive diagnostic test for diastolic dysfunction using supine bicycle exercise Doppler echocardiography. J Am Soc Echocardiogr 2005, 18:63-68.

21. Kitzman DW, Higginbotham MB, Cobb FR, Sheikh KH, Sullivan MJ: Exercise intolerance in patients with heart failure and preserved left ventricular systolic function: failure of the Frank-Starling mechanism. J Am Coll Cardiol 1991, 17:1065-1072.

22. Acarturk E, Koc M, Bozkurt A, Unal I: Left atrial size may predict exercise capacity and cardiovascular events in patients with heart failure. Tex Heart Inst I 2008, 35:136-143.

23. Vaturi M, Hadar T, Yedidya I, Shapira Y, Monakier D, Weisenberg DE, Sagie A: The association of left atrial volume with exercise capacity in patients with chronic severe mitral regurgitation. Isr Med Assoc J 2010, 12:150-153.

24. Saraiva RM, Demirkol S, Buakhamsri A, Greenberg N, Popović ZB, Thomas $J D$, Klein AL: Left atrial strain measured by two-dimensional speckle tracking represents a new tool to evaluate left atrial function. J Am Soc Echocardiogr 2010, 23:172-180.

25. Kusunose K, Motoki H, Popovic ZB, Thomas JD, Klein AL, Marwick TH: Independent association of left atrial function with exercise capacity in patients with preserved ejection fraction. Heart 2012, 98:1311-1317.

doi:10.1186/1476-7120-12-19

Cite this article as: Ratanasit et al.: Left atrial volume as an independent predictor of exercise capacity in patients with isolated diastolic dysfunction presented with exertional dyspnea. Cardiovascular Ultrasound 2014 12:19.

\section{Submit your next manuscript to BioMed Central and take full advantage of:}

- Convenient online submission

- Thorough peer review

- No space constraints or color figure charges

- Immediate publication on acceptance

- Inclusion in PubMed, CAS, Scopus and Google Scholar

- Research which is freely available for redistribution 